\title{
Empirical Study of Airline Service Dimensions in China
}

\author{
Jianling Wang, Junyan Wu, Lingyun Wang, and Min Li
}

\begin{abstract}
With the rapid growth of China's national economy and the improvement of people's living standards, airline market has increased quickly, understanding customer demand of airline market is critical to the industry development. In this paper, a empirical study of airline service demand in China is explored with factor analysis, and five dimensions are extracted which named with Comfort need, Safety and Convenience need, Time need, Brand and promotion need, and Price need. The result verifies some former research, and shows some difference with developed countries.
\end{abstract}

Index Terms-Airline service, civil aviation, customer expectation, dimension.

\section{INTRODUCTION}

In the 21st century, with the rapid growth of China's national economy and the improvement of people's living standards, airline transport, as a mode of transport for a people to travel, plays an increasingly important role, and China civil aviation industry shows a rapid development momentum. The number of air travelers in China tripled from 2000 to 2009 , and airline passengers had increased at an average annual growth rate of $20 \%$ in the 1996-2009 period. According to the forecast of the International Air Transport Association, China will be the world's fastest growing air passenger transport market in the next 25 years.

Along with the huge demand for air passenger transport, due to changes in the internal and external environment, there have been many problems of China Civil Aviation. For instance, the participation of the private airlines and low-cost airlines makes the low-cost and harsh competition between airlines in the Chinese market. Serious homogenization of products and services, the low quality of service, airport congestion at peak times, the increased flight delays and the intense impact of high-speed rail, all these problems make a fierce competition between China Airlines and revenue is greatly affected. However, there is lack of in-depth understanding of airline service market demand. In this background, it is a critical issue for Airline Company to explore customer demand deeply and exert an effective marketing strategy.

\footnotetext{
Manuscript received March 25, 2003; revised May 28, 2013. This work was supported in part by NUAA Research Funding (NR2011009), IBM Global Shared University Research "Customer Behavior Analytics in Multi-channel Scenario", NSFC70902026.

The authors are with the Nanjing University of Aeronautics and Astronautics. She is now with the College of Economics and Management, Nanjing, China (e-mail: WJL7520@126.com, wjyjunyan@126.com, helwly@163.com, lingxao666@126.com).
}

\section{ITERATURE REVIEW}

\section{A. The Importance of Airline Service Demand}

Scholars have paid great attention to the demand for air passenger transport market in the early 20th century. Kandampully and Duddy (1999) consider demand plays an important role. To create superior value for customers that requires detailed understanding of the needs and expectations of customers, it is not just now, and it would last 20 years . At the same time, they also pointed out that whether the company can meet the present and future, short-term and long-term consumers' needs decides the competitive advantage of a business. By empirical research, Gustafsson, Ekdahl and Edvardsson ( 1999 ) find we need a deep understanding of customers' needs, expectations and preferences to develop successful customer service [2]. It is the understanding of consumer needs, which can improve operational efficiency and formulate a good marketing strategy to increase consumer satisfaction, that have been identified as the key factors of the airline's survival and achieving competitive success. In order to implement marketing strategies to meet consumer purposes, airlines must give full consideration to the different expectations and perceptions of the passengers [3]. Aksoy, Atilgan and Akinci (2003) finds passenger's service demand expectations greatly affect the airline's service strategy decisions, and demographic characteristics play a key role in the formation process of the customer needs [4]. Generally, the air passenger market is a highly competitive market, and airlines need to constantly improve their quality of service to enhance the competitiveness [5].

Along with the rapid development of China civil aviation, civil aviation industry has become the focus of scholars. More and more scholars research of China aviation market, which mainly focuses on the study of trend of aviation passenger transport market and market structure. For example, based on the analysis of the characteristics of the China civil aviation transport market and passengers, Yu Jian (2004) sums up the characteristics of the domestic market. As for official data, Civil Aviation Administration of China Aviation Safety Technology Center publishes the lasted information about Chinese civil aviation every year. In the reports, they analyze the market structure of China aviation passenger transport. The surveys cover traveling purpose, occupation, ways to buy tickets, frequency of air travel in the last year, seating room and so on. Based on the statistics data, the agent summarizes characteristics of China aviation passenger transport market.

\section{B. Dimensions of Airline Service Demand}

In terms of consumer demand, the products and services provided by the airlines are what consumers demand. This 
demand is specifically reflected in the choice of airlines, aircraft, cabin features, punctuality, and service and so on. Only by understanding the differences of consumer demand for air passenger transport, can airlines enter the market and do the positioning of the target market. Airlines plan of products and services, provide a variety of products and services in different markets, also make ensure of the quality of products and services.

Through the analysis of British aviation market, Doganis and Graham (1987) think the customers would consider the following factors in the choice of flights and airlines: air fares, flight routes, flight frequency, time of departure, punctuality rate, change trains, ground and cabin service, in-flight entertainment system, cabin layout, models, safety and credibility, brand image, the frequent flyer programs, advertising and market positioning [6]. Through the analysis of the Japanese air passenger market, Aksoy, Atilgan and Akinci (2003) sort out a variety of factors. They summarize Japanese consumers in the selection of airlines would be more emphasis on this eight factors: cabin and personnel, marketing strategies, food and beverage service, free alcoholic beverages, equipment, network services, punctuality rate and speed, air fares [7]. Young, Cunningham and Lee (1994) point out that consumers focus on in-flight comfort and the operational efficiency of the routes [8]. Chang and Yeh (2002) propose passenger focus on the comfort of the environment, service personnel, safety and reliability, and service convenience [9]. Chen and Chang (2005) think the products and services provided by the airlines have the fixed and flexible features. The service with fixed features is the size of seat, cargo storage, aircraft type. The service with flexible features is the meal services, the flight attendants and other tangible and intangible services provided by airline companies [10].

As for literatures written in English, scholars do lots of research on how the product and service characteristics affect consumer behavior in the air passenger market. Compared with that, we find few researches are published in Chinese. Chen Jiaxian (2009) use the comfortable cabin, food and beverage service, service personnel, check-in time, environment, luggage space, punctuality rate, safety and other factors, and do research on that factors how to affect the quality of service from the five aspects of the service model. Jiang Liang (2007) does research on the industry demand and supply chain optimization, using seven factors to study consumer buying behavior. The factors include airline, air fares, models, flight time, ground and cabin service, the frequent flyer programs and direct flights. The user evaluation activities conducted a survey of industry passenger market structure in a random sampling way done by China Civil Aviation Administration of Aviation Safety Technology Center. In the survey, Li Hongtao (2010) use the eight main factors that is safety, flight schedule, airline brand, fares, service, flight punctuality, models and frequent flyer.

\section{RESEARCH AND DESIGN}

\section{A. The Questionnaire Design Steps}

The questionnaire design of the air passenger transport market demand of this study is mainly based on the following three steps:

1) The preparation of the initial questionnaire. Because this study which involved in the factors of air passenger transport demand differences and demand variables has some basis research in domestic and foreign .This research is done by the Civil Aviation Administration of China Aviation Safety Technology Center"2008 Civil Aviation" .The domestic civil aviation passenger transport market constitutes the basic of questionnaire. Combining with the reference of Jiang Liang and Safak Aksoy's scale used in the analysis of various factors, through the further study of the relevant literature, we discuss with mentors and academic team members, interview with frequent travelers on the part of the air passenger transport market, revise the questionnaire, and form the initial questionnaire.

2) The preliminary investigation and study. Because the scale of the research items is identified from comprehensive study of domestic and foreign scholars, and applicable conditions and objects are different, these scales may not be in line with our air passenger transport market. In order to check the quality of the initial questionnaire, we take a small sample of preliminary investigation and study. The investigation mainly targeted at the friends who often travel by plane and have a better understanding of aviation products and services. Through reliability test on the recovery of the initial questionnaire, and theoretical analyzes, we further modify the questionnaire, and ultimately form a formal questionnaire.

3) The formal investigation and study. The respondents are the aircraft passengers and do the paper questionnaires. Paper questionnaires issued in Nanjing Lukou International Airport. We issued to the passengers in the departure lounge and passengers who are just off the plane in the airport pick port, the main respondent are waiting travelers. Nanjing Lukou International Airport passenger throughput is more than 40 million passengers, the throughput is large, and flights distribute in regional plate of China civil aviation. It is navigable with, not only including China Eastern Airlines, China Southern Airlines, China International Airlines, Hainan Airlines and other major airlines, but also medium-sized airlines, including Shenzhen Airlines, Xiamen Airlines, and Sichuan Airlines. It is also navigable with Lufthansa, Japan Airlines and other foreign airlines. Therefore, route coverage and passenger carrying capacity of this airline can achieve the requirements of the survey.

The questionnaires issued a total of 400 paper questionnaires, 60 the electronic Questionnaires, and we took back 335 questionnaires. We excluded 41 invalid questionnaires whose answer was obvious regularity or which had two and above items that did not answer, and 14 questionnaires were removed because the respondents took the foreign airlines. The final effective questionnaire is 280 , including 51 network questionnaires and 229 paper questionnaires. The effective recovery rate is $60.86 \%$. During the investigation, vast majority of respondents are interested in the study, and willing to cooperate with us. The 
quality of questionnaire is high.

\section{B. The Contents of the Questionnaires}

\section{1) The itinerary information of respondents}

The entire questionnaire is divided into three parts. the first part contains these problems. Respondents are asked to fill in the name of airline, the departure and the destination and characteristics variables which reflect the personal itinerary (travel purposes, flight frequency, and expenses origin) and other basic issues. This part of the questionnaire is used to verify the coverage of questionnaire data, and support the correlation analysis of air passenger transport market demand.

\section{2) Demand for air services}

This part uses 7 point Likert scale. We List in sixteen consumer demand of China air passenger transport market, let consumers to score the importance of each demand, with unimportant meaning " 1 " and most important $m$ " 7 ". We hope to identify the service demand dimension by factor analysis.

\section{3) Customer profiles}

The third part of the subject is the investigation of the basic information of the respondents, including gender, age, education level and income; these basic information collections of investigators are consumer personal attributes variables in analysis of demand differences.

\section{CUSTOMER Profines}

The age distribution is mainly concentrated in the 21-30 years old and 31-40 years old, accounting for $81.7 \%$.This data is similar with the 2009 civil aviation passenger statistics data which was exhibited by Administration of China Aviation Safety Technology Center (ACASTC). In 2009, passengers of 21-44 years old are the main part of the civil aviation passengers, accounting for the proportion of $77.06 \%$.

As for gender, the number of men is a little more slightly than women, which is consistent with our existing population structure.

The educational level focuses on the college for professional training and university, and the college degree or above accounts for $93.2 \%$. This data is similar with the 2009 civil aviation passenger statistics data which was exhibited by (ACASTC). In 2009, the passengers with college degree or above accounts for $75.84 \%$, constituting the main body of the civil aviation passengers.

Annual household income is mainly concentrated in the 5-10 million and 10-15 million income segments, this data is also in line with the level of consumption of the air passenger market.

The trip purpose is mainly for business affairs, accounting for $42.9 \%$.Tourism travel is the next, and accounting for $28.9 \%$.The proportion of business affairs and tourism travel accumulates to $71.8 \%$.This data is similar with the 2009 civil aviation passenger statistics data. In 2009, business passengers is the highest proportion of civil aviation passengers, accounting for $41.6 \%$, is the main part of the civil aviation passengers. Tourism travel is the next, accounting for $33.12 \%$.
Travel frequency mainly focuses on 1-2 times and 2-5 times, and account for $74.3 \%$. This data is similar with the 2009 civil aviation passenger statistics data which was exhibited by Civil Aviation Administration of China Aviation Safety Technology Center.

In terms of expense, it accounts for $50.7 \%$ at their own expense and it accounts for $38.2 \%$ at public expense, and the ACASTC statistics exhibit that travelers at their own expense accounts for proportion of $56.46 \%$ in 2009. The next is passengers at public expense accounting for $43.54 \%$. From the survey data, we can find that the gap between the public expense and own expense gradually increases.

Contrast with the 2009 survey done by ACASTC, we find the air passenger profiles consistent with the current situation of China air passenger transport demand. Through the analysis of the above data and summary of the existing survey data, we can summarize the following characteristics:

1) The age of the main consumer of China air passenger transport is mainly in 21-40 years old, which means young and middle-aged population is the main consumer.

2) The number of male flight passengers is more than the number of women passengers.

3) The educational level of consumer groups is relatively high, mainly in the college, undergraduate and graduate degree.

4) Chinese air travel crowd have higher household income with certain economic basis.

5) The main travel purpose is business travel, followed by tourism travel.And the number of tourism travel traveler increase.

6) On the whole, travel frequency is few, more than $60 \%$ of passengers travel less than 6 times every year.

7) The proportion of public travel travelers gradually decreases, and the number of passengers at owns expense now exceeds the number of passengers at public expense.

\section{The AnAlysis of Airline SERVICE DEMAND}

In order to investigate Chinese airline service demand deeply, we combine the eight factors used in the investigation of the air passenger market structure by the committee of China Civil Aviation Association (CCAA), and demand factors proposed by some scholars. In this paper, we initially selects sixteen factors as demand content options, not only including eight factors used in the investigation of the air passenger market structure by the user work committee of CCAA (Airline brand, fares, aircraft type, time, flight punctuality, service, frequent flyer program, security), but also including flight density, direct flights, the quality of food and drink, the cabin environment, in-flight entertainment equipment and personal space. In this part, we use the exploratory factor analysis to explore the air service demand dimensions.

\section{A. Descriptive Statistical Analysis of the Airline Services Demand}

Through the sorting of mean size of the air passenger market demand, we can get the descending order of the 
importance. From the sequence, we can find that the mean value of the sixteen factors is all above 4 points. This exhibits that these factors are important factors considered by consumers. The sequence of flight safety, direct flights, flight punctuality, Cabin environment, in-flight service, departure time, Food and beverage services, fare, ground services, landing time and flight route density, airline brand is in the middle; while the sequence of personal space, aircraft models, the frequent flyer program, and in-flight entertainment equipment are rearward. Flight security is the most importance factors. Everyone agreed that fares have much impact on demand, but the fare ranks in the middle position. The in-flight entertainment equipment is classified as the least important factor. Although the important degree of sequence has some difference, the overall important degree is similar with the 2009 civil aviation passenger statistics data, where Passengers consider that the safety is the primary factor, accounting for the proportion of $34.94 \%$.

TABLE I: THE ARRANGEMENT OF CHANNELS

\begin{tabular}{llll}
\hline \hline \multicolumn{1}{c}{ Customer Demand } & \multicolumn{1}{c}{ N } & Mean & St. D. \\
\hline Flight Safety & 280 & 6.39 & .893 \\
Direct Flight & 280 & 5.99 & 1.155 \\
Punctuality & 280 & 5.78 & 1.097 \\
Cabin Environment & 280 & 5.71 & 1.076 \\
In-flight Service & 280 & 5.67 & 1.043 \\
Departure Time & 280 & 5.52 & 1.139 \\
Food and Beverage & 280 & 5.48 & 1.212 \\
Service & & 5.44 & 1.368 \\
Ticket Fare & 280 & 5.36 & 1.301 \\
Ground Service & 280 & 5.29 & 1.437 \\
Landing Time & 280 & 5.11 & 1.494 \\
Flight Route Density & 280 & 4.85 & 1.523 \\
Airline Brand & 280 & 4.82 & 1.283 \\
Personal Seat Space & 280 & 4.70 & 1.464 \\
Aircraft Model & 280 & 4.56 & 1.482 \\
Frequent Flyer & 280 & & \\
Program & & 4.32 & 1.458 \\
In-flight Entertainment & 280 & & \\
Equipment & & & \\
\hline \hline
\end{tabular}

\section{B. The Analysis of Airline Service Demand Dimension}

In order to explore the internal structure relationship among the sixteen factors, we need to carry out further analysis. It the air passenger market, consumers demand includes a total of 16 items. We do the Cronbach $\alpha$ coefficient test using SPSS17.0 .The result exhibits that the Cronbach $\alpha$ coefficient is $0.853>0.80$. For scale with good reliability, exploratory factor analysis is used.

Through the analysis of the simple correlation coefficient of the sixteen demand factors, almost all of the simple correlation coefficients of variables are greater than 3 . It is in line with the fundamental premise of the factor analysis. Through the KMO and Bartlett's Test of Sphericity for factor analysis, we get the value of KMO Test is 0.776 , which is higher than acceptable baseline 0.7. In the Bartlett's Test, the p-value is $0.000<0.001\left(x^{2}=781.838\right)$, exhibiting factor analysis can be carried out once again.

Exploratory factor analysis is used to analyze the data of sixteen demand factors. We extract the common factor, and get the initial loading matrix. Due to the strong correlation among the air passenger market factors, in this study, we use promax rotated correlation matrix to analyze the factors and get the factor loading matrix. The five extracted common factor accumulatively explained $72.331 \%$ of the total variance. It is in line with the general standard of sociology cumulative contribution rate of $60 \%$. The rotated factor pattern matrix is shown as following (table 2).

TABLE II: THE PATTERn MATRIX OF AIRLINE SERVICE DEMAND

\begin{tabular}{|c|c|c|c|c|c|}
\hline \multirow{2}{*}{ Customer Demand } & \multicolumn{5}{|c|}{ component } \\
\hline & 1 & 2 & 3 & 4 & 5 \\
\hline In-flight Service & .837 & & & & \\
\hline Food and Beverage Service & .825 & & & & \\
\hline Cabin Environment & .761 & & & & \\
\hline Personal Seat Space & .703 & & & & \\
\hline Direct Flight & & .860 & & & \\
\hline Flight Safety & & .794 & & & \\
\hline Ground Service & & 687 & & & \\
\hline Departure Time & & & .909 & & \\
\hline Punctuality & & & .823 & & \\
\hline Landing Time & & & .652 & & \\
\hline Flight Route Density & & & .572 & & \\
\hline Aircraft Model & & & & .715 & \\
\hline Frequent Flyer Program & & & & .688 & \\
\hline Airline Brand & & & & .567 & \\
\hline In-flight Entertainment & & & & 532 & \\
\hline Equipment & & & & .532 & \\
\hline Ticket Fare & & & & & .927 \\
\hline $\begin{array}{l}\text { Extraction method: principal } \\
\text { Rotation method: promax }\end{array}$ & mponen & & & & \\
\hline
\end{tabular}

1) Factor 1: including the flight attendant service, the quality of food and beverage, cabin environmental comfort, personal space, which mainly reflects on airline service, can be named "Comfort need".

2) Factor 2: including the direct flights, safety, and ground services, which reflect consumer demand for convenience and security, can be named "Safety and Convenience need".

3) Factor 3: including the flight departure time, punctuality rate, landing time and flight density, which reflect customer time requirements, can be named "Time need".

4) Factor 4: including the aircraft models, frequent flyer program, the airline brand and entertainment equipment on the aircraft, which reflect consumer demand for the airline brand and promotional strategies, can be named "Brand and promotion need".

5) Factor 5: including airline fares, which reflect consumer demand for price, can be named "Price need".

\section{RESUlTS AND DISCUSSION}

The total explanation rate of the five demand dimension is $72.331 \%$.Due to these five dimensions, except that the "price need" dimension is single factor; the other four factors have more than three explanatory variables. Therefore, through the reliability analysis of these four factors, we calculate the Cronbach coefficients that respectively are $0.891,0.853$, 0.804 and 0.781 . Reliability analysis exhibits that the reliability of these factors are fully consistent with the 
statistical requirements.

Through the analysis of consumers demand in China air passenger transport market, we verify some foreign scholars' research results from the extracted demand factors. Although the Price needs factor contains only one of the questions, the result is the same as the research done by Safak Aksoy on the consumer price demand dimension in Japan Airlines passenger market(only containing one item).(Safak Aksoy 2003) The results also verify the comfort ,flight operations and efficiency, which is proposed by Young (Young 1994); the comfort and timeliness, which is proposed by Waikar and Nichols (Waikar and Nichols 1997); the time efficiency which is proposed by Rhoades (Rhoades 1998); the comfort on the plane, airline personnel, safety, reliability, and convenience of service, which is proposed by Chang and Yeh (Chang and Yeh 2002).Through the analysis of the British aviation market, Rigas Doganis proposes the factors of airline fares, flight schedule, the comfort and brand image. Through the analysis of Japan aviation market, Japanese scholars propose eight factors: ticket fares, cabin and personnel, the flight route and marketing strategy, food and beverage service, equipment, network services, punctuality and speed, free alcoholic beverages.

That can be seen from the analysis of internal structure of the demand, although the development of China air passenger transport market compared with the developed countries markets (such as the UK and Japan) is not sufficient, there are also on the internal structure of the correlation among consumer demand in the China air passenger transport market, and it is similar with the foreign consumers in price need, comfort need, convenience need, and time demand. On the other hand, the factors extracted and indexes contained in the factor are both some different with developed countries, especially in the brand and promotion strategies. This also reflects the homogenization of products and services in China airline market, and consumers show a rather ambiguous status in the demand for products and services.

\section{REFERENCES}

[1] J. Kandampully and R. Duddy, "Competitive advantage through anticipation, innovation and relationships," Management Decision, vol. 37, no. 1, pp. 51-56, 1999.

[2] A. Gustafsson, F. Ekdahl, and B. Edvardsson, "Customer focused service development in practice-a case study at Scandinavian Airlines System (SAS)," International Journal of Service Industry Management, vol. 10, no. 4, pp. 344-58, 1999.
[3] F. Sultan and M. C. Simpson, "International service variants: airline passenger expectations and perceptions of service quality," Journal of Services Marketing, vol. 14, no. 3, pp. 188-216, 2000.

[4] S. Aksoy, E. Atilgan, and S. Akinci, "Airline services marketing by domestic and foreign firms: differences from the customers' viewpoint," Journal of Air Transport Management, vol. 9, no. 6, pp. 343-51, 2003.

[5] M. An and Y. Noh, "Airline customer satisfaction and loyalty: impact of in-flight service quality," Service Business, vol. 3, no. 3, pp. 293-307, 2009.

[6] R. Doganis and A. Graham, "Airport management: the role of performance indicators," Research Report Transport Studies Group, vol. 13, 1987.

[7] S. Aksoy, E. Atilgan, and S. Akinci, "Airline services marketing by domestic and foreign firms: differences from the customers" viewpoint," Journal of Air Transport Management, vol. 9, no. 6, pp. 343-51, 2003

[8] Y. H. Chang and C. H. Yeh, "A survey analysis of service quality for domestic airlines," European Journal of Operational Research , vol. 139, no. 1, pp. 166-77, 2002.

[9] F. Y.Chen and Y. H. Chang, "Examining airline service quality from a process perspective," Journal of Air Transport Management vol. 11, no. 2, pp. 79-87, 2005.

[10] C. Young, L. Cunningham, and M. Lee, "Assessing service quality as an effective management tool: the case of the airline industry," Journal of Marketing Theory and Practice, pp. 76-96, 1994.

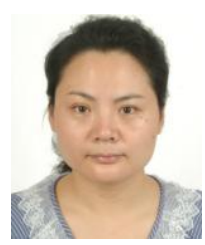

Jianling Wang is an associate professor with economics and management college at Nanjing University of Aeronautics and Astronautics. Her research focuses on service science, marketing decision, and customer satisfaction.

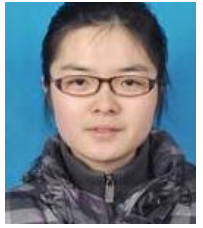

Junyan $\mathbf{W u}$ is a master student of with economics and management college at Nanjing University of Aeronautics and Astronautics. Her research focuses on strategy management and service management.

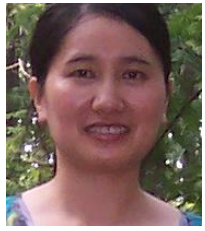

Lingyun Wang is an associate professor with economics and management college at Nanjing University of Aeronautics and Astronautics. Her research focuses on marketing decision, and organizational behavior.

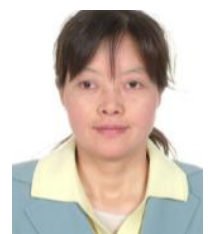

$\mathbf{M i n} \mathbf{L i}$ is an associate professor with economics and management college at Nanjing University of Aeronautics and Astronautics. Her research focuses on marketing decision, and culture management. 